\title{
Establishing a Training Mode for English-Innovative Talents in the Context of Diversified Education
}

\author{
Lingchao Wang ${ }^{1, a}$, Han Yan ${ }^{2, b}$ \\ ${ }^{1}$ Liaoning Railway Vocational and Technical College, Jinzhou, 121000, China \\ 'Jinzhou Teachers' Training College, Jinzhou, 121000, China \\ a275319814@qq.com, b42444787@qq.com
}

\begin{abstract}
Keywords: cognitive approach; Japanese teaching; enlightenment; theoretical basis; teaching process
\end{abstract}

\begin{abstract}
Talent-training should be based on the needs of society. Training innovation-oriented talents is both the urgent need of constructing an innovative country in the new era, and the need of higher-education institutions to reform and develop themselves. Since the training mode is one of the key factors that affect the quality of talent-training, higher-education institutions shall create a training mode that suits educational objectives so as to achieve the above mentioned goals. On the basis of the factual situation of socialist market economy of our country, and from both theory and practice, this paper studies deeply into the trend of the demand for English talents and the mode for training these talents, and finds that it is an inexorable trend of the era to cultivate English-innovative talents. The paper mainly researches the forms for training innovative talents, the curriculum model, and the solutions, and proposes related practical measures. Comprehending the connotation of innovation-oriented talents and the characteristics of the innovative talents of English major is beneficial to reform and innovate on the mode of training the innovative English talents. Colleges and universities should start with transforming educational ideas and constructing a team of English teachers who possess innovative knowledge, and then reform the course structure, teaching contents, and teaching methods, adopt the classroom-teaching mode that benefits the cultivation of innovative talents, provide extracurricular courses and incentive mechanisms, expand the opportunities for students to practice and innovate, and strengthen the innovation ability of students to make them stand firmly in the social competition.
\end{abstract}

\section{Introduction}

The primary mission of colleges is to provide more and more elites for the society. With the continuous development of the society, what kinds of talents the colleges of our country should 5cultivate has become the key element of the mission. According to the report of Comrade Jiang Zemin at the 16th CPC National Congress, we should lay emphasis on the innovative type of education and constantly improve it to provide more high-quality professional talents for the society, which is based on cultivating innovative talents. Higher Education Syllabus for English Majors (2000) pinpoints that in the training plan for modern English talents, more new goals shall be set-English majors in colleges and universities shall be equipped with more abundant knowledge about English language and solid knowledge of culture; they should be able to skillfully apply English to foreign communication, education, economy and trade, culture, science and technology, and military affairs and so on; more comprehensive talents shall be developed in translation, teaching, management, and research and other fields. On the basis of the factual situation of socialist market economy of our country, supported by theory and practice, this paper studies deeper into the developing form of English talents and the situation of training English talents, and proposes that it is an inexorable trend of the era to cultivate English-innovative talents.

\section{The Development Direction of the Concept of English Talents}

English education is closely correlated with the foreign policy and economic construction of our 
country. The mission and goal of English education vary from environment to environment, from period to period. During a long period after the birth of new China, the main mission of English education is to cultivate students' ability to listen, speak, read, and write, to train more talents with comprehensive qualities who can undertake the job of translation, especially written translation, to help people read more English documents. However, the ability to communicate by English in actual cultural contexts is neglected. With the deepening of reform and opening up, especially the development of foreign trade and economic activities, foreign affairs have grown up, which leads to that developing multi-talents is the key component of foreign language education. In our country many higher education institutes established English major. Those English majors who are also familiar with certain professional knowledge are getting more and more attention of the market. With the constant development of social economy, our country's influences on international politics, economy, culture, and science and technology are strengthened and diverse forms of culture come into being, which makes it difficult for multi-talents to suit the development and demands of the market that needs more talents with professional ability and knowledge of foreign language, i.e. innovative talents. They play an important role in international communication and work innovatively. Therefore, during the course of development in the future, those talents who take foreign languages as a mere instrument cannot adapt to the actual developing form of the market any longer, which threatens their survival. Only interdisciplinary talents of foreign language majors can keep pace with the ever-developing society. Similarly, English majors should also be innovative talents to better solve the problems in foreign communication, politics, economy, and culture and so on.

\section{Training Forms of English-Innovative Talents}

\section{(1) Related Systems of Training English-Innovative Talents}

Training forms, born in the environment of social economy and politics, are the plans for the main parts, procedures, and methods of teaching, and are closely related with educational objectives. In the past, the form of training English talents stresses the deep research into many theoretical courses that require the students to study the corresponding professional theories, which makes the scope of knowledge and subjects that the students learn very monotonous and makes the students comparatively weak in practice and less powerful in innovation. The cultivation of English-innovative talents needs us to keep transforming the education model of training talents, to explore more English education systems that are characterized with fusion, transformation, and diversification, and to propose solutions that can solve the problems of the traditional training forms of English talents and improve the training standard. Cultivating English-innovative talents is a new type of training talents, which proposes higher requirements and stricter codes for training English talents. For the sake of the development of socialist market, and especially due to the deepening of our country's strategy of reform and opening up, the structure of the courses are flexible to some extent, which is beneficial to the professional completion of the training task and basic training target. So, we still need theoretical researchers and we also need professional researchers in the fields of linguistics, foreign literature, comparative literature studies, and foreign literature review. We can let those students who have interests and specialties do corresponding theoretical research of language and literature, and let them choose related courses to study. After the undergraduate period, the students can also receive further education during postgraduate period.

\section{(2)Curriculum Construction and Teaching Material Suitable for Training English-Innovative Talents}

Nowadays foreign language education in colleges and universities are always in revolution, which makes curriculum construction very important for curricula are the embodiment of cultivating tasks and principles and the key to cultivate English talents. The curriculum construction of practical English should adapt to the realistic demand of the development of socialist market. We need to research deeply the logical structure of the curriculum design according to the reality of curriculum construction to conform to the cognitive rules of the students. The target of training English-innovative talents also has requirements on the curriculum. The curriculum system of 
practical English is neither a mere combination, nor created by adding practical courses to the past teaching plan or adding some certain training. We should depend on the cultivating task and specification for English-innovative talents, combine effectively basis and application, theory and practice, selective course and required course, set one or two foreign languages as tool and one or two interdisciplinary majors as direction to make a curriculum system and course modules with clear goals, complete mechanism, and optimized structure. All of the above is to ensure the integrity, continuity, and the systematicness of the knowledge structure, to provide more English-innovative talents who possess innovative knowledge, innovative ability, innovative performance, and other innovative traits.

\section{(3) Main Modes of Training English-Innovative Talents}

It takes more professional knowledge and corresponding abilities to be English-innovative talents, which require stressing diversion cultivation when cultivating the talents. The senior class students should select courses in and out of the department or school according to their own hobbies, goals, and the actual market needs, thus giving students more choices, which is better suitable for cultivating English-innovative talents. During diversion cultivation, the students' ability to work independently should also be emphasized and combined with the knowledge of basic courses to strengthen the English proficiency, independent researching ability, public relation ability, cooperation capability, and organizing and managing ability of the students, especially their ability to apply English knowledge to daily life. Taking junior colleges for example, this kind of training mode consists of three stages:

Stage 1 (first to third semester) - stage for cultivating English proficiency. Colleges recruit students according to different departments instead of majors, which can avoid the cultural loss of the students for their incomplete recognition of professional knowledge. The increase of disciplinary directions gives the students broader space to choose their majors including disciplines. In this process, the main task is to construct the courses that are covered in the practical course modules of English language. With more difficulty, the practical course costs much time and needs practicing and explaining repeatedly. Only in this way can the students improve their English language ability and accomplish the expected tasks. In terms of the course construction, the mode of low credits required course or selective course can be applied to make the students master basic knowledge. Language learning is different from the related subjects for language environment and cultural environment have some extent of edifying function. We can introduce foreign teachers to teach and we can take advantage of CCTV, foreign language reference room, English broadcast, English speech contest, thematic English lecture, and English Corner and other teaching modes, to construct a relaxing and pleasant atmosphere, to make the students can learn English at any time. Through continuous edification, a solid base of English learning can be established for the students.

Stage 2 (fourth to fifth semester) - stage for diversion cultivation of the composite abilities and innovative ability of the students. During this stage, students are able to select courses in and out of the department or school even choose interdisciplinary major according to the market needs and their own hobbies, which is better for cultivating the composite abilities and innovative ability of the students. The students can choose the corresponding courses as elective courses such as public relations, secretarial services, foreign trade, tourism, business, finance and economics, teacher training, computer etc. The scores, credits, certificates of elective courses can also be recognized and accepted. However, for English department, the scope of the students' choices should be moderately controlled. All the corresponding courses in a language module can be opened and the form of low credits elective course can be applied. The corresponding courses in the module of cultural courses can be added, and the mode of elective course or appreciation course.

Stage 3 (sixth semester) - stage for internship and job-seeking. During this stage, students can make contact with the company for internship according to their own hobbies and the market needs, effectively combine them with career choice, and strengthen their abilities of social intercourse, communication, public relations, practice, flexibility, problem-solving and adaptation etc. during internship. Therefore, on a solid base of professional knowledge, only those students who know well about two foreign languages and possess interdisciplinary specialty and pragmatic competence 
can satisfy the factual demands of the society. Graduates can also make efforts towards the above direction.

\section{The Characteristics of English-Innovative Talents}

(1) Solid basic English skills. Basic skills hold great significance for learning any language. Innovation should be based on them to cultivate English-innovative talents for the society.

(2) Strong professional knowledge of English, with which the cultural literacy of English can be improved and the knowledge structure of English can be completed. This is useful for the further study of English and getting acquainted with the professional knowledge in other fields meanwhile.

(3) The spirit and ability of innovation. English-innovative talents have certain level of innovation ability, the capability of solving problems independently, unique personal comprehension for things, and certain level of critical thinking.

(4) Intercultural communication competence. As an international language, English is a communication course. It is important to know about the customs of different cultures. Language is both the carrier and a component of culture and they are mutually dependent, so it is advantageous to English communication skills to know the social-cultural context.

(5) Good psychological quality. The modern society poses higher demands for the psychological quality of English-innovative talents. Psychological adaptability refers to the ability of adjusting oneself. The talents' psychological adaptability and the ability to withstand setbacks should be improved to make them better adapt to the external world.

\section{Conclusion}

With the continuous development of the social economy, the present market and society are demanding more and more of the English talents. For instance, Huang Yuanshen supposes that the demands of the society for English talents gradually show a diversified trend. Those English talents who possess only English knowledge and basic skills in the past cannot fit the development of the era any more. The shortcomings of the market economy are increasing, so colleges and universities should cultivate more interdisciplinary English talents, and then we can make greater contribution to the development and advancement of the society.

\section{References}

[1] Chen Weiwei. Study of Innovative English Class in Medical Nutrition Industry [J].Overseas English, 2013, (12).

[2] Lin Qi. Analysis of Collaborative Courses in the Model of Innovative English Education [J]. China After School Education,2014, (6) .

[3] Zhang Xueqin. On Innovation of classroom teaching mode of business English in Higher Vocational Education[J]. Curriculum Education Research (New Teachers' Teaching), 2013, (16).

[4] Jia Lufang. A Brief Talk on cultivating students' innovative ability in teaching of English in secondary vocational school [J]. Middle school students' English (Foreign Language Teaching and Research), 2013,(10).

[5] Guo Xuedan. Construction of Diversified Talent-Training Model for Higher Vocational English Major [J]. China After School Education , 2012 (33).

[6] Huang Yuanshen. Talents with Mixed Abilities in 21st Century [J]. Foreign Language World, 2001 (1). 